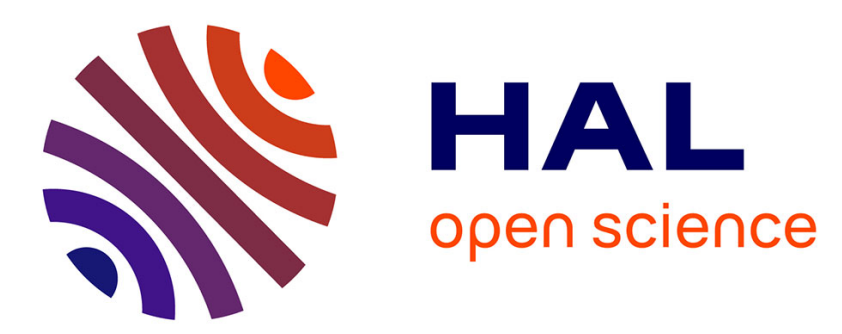

\title{
Transport coefficients of high temperature N2-H2 mixtures
}

\author{
M. Capitelli, C. Gorse, Pierre Fauchais
}

\section{To cite this version:}

M. Capitelli, C. Gorse, Pierre Fauchais. Transport coefficients of high temperature N2-H2 mixtures. Journal de Physique, 1977, 38 (6), pp.653-657. 10.1051/jphys:01977003806065300 . jpa-00208624

\section{HAL Id: jpa-00208624 https://hal.science/jpa-00208624}

Submitted on 1 Jan 1977

HAL is a multi-disciplinary open access archive for the deposit and dissemination of scientific research documents, whether they are published or not. The documents may come from teaching and research institutions in France or abroad, or from public or private research centers.
L'archive ouverte pluridisciplinaire HAL, est destinée au dépôt et à la diffusion de documents scientifiques de niveau recherche, publiés ou non, émanant des établissements d'enseignement et de recherche français ou étrangers, des laboratoires publics ou privés. 
TRANSPORT COEFFICIENTS OF HIGH TEMPERATURE $\mathbf{N}_{2}-\mathrm{H}_{2}$ MIXTURES $\left(^{*}\right)$

\author{
M. CAPITELLI, C. GORSE
}

Centro di Studio per la Chimica dei Plasmi del C.N.R.

Dipartimento di Chimica dell' Università di Bari, Via Amendola 173 (Italy)

and

\title{
P. FAUCHAIS
}

Laboratoire de Thermodynamique-UER des Sciences, Limoges (France)

(Reçu le 30 décembre 1976, accepté le 4 mars 1977)

Résumé. - Les coefficients de transport (conductivité thermique totale, viscosité, conductivité électrique) des mélanges $\mathrm{N}_{2}-\mathrm{H}_{2}$ ont été calculés, à la pression atmosphérique, dans tout l'intervalle de température $2000 \mathrm{~K}-20000 \mathrm{~K}$. Les résultats ont été obtenus en utilisant les approximations supérieures de la méthode de Chapman-Enskog, après une sélection appropriée des intégrales de collision. La précision des résultats est discutée et quelques-uns de ces résultats ont été comparés à des valeurs expérimentales.

Abstract. - The transport coefficients (total thermal conductivity, viscosity, and electrical conductivity) of $\mathrm{N}_{2}-\mathrm{H}_{2}$ mixtures have been calculated in the temperature range $2000 \mathrm{~K}-20000 \mathrm{~K}$. The results have been obtained by means of higher Chapman-Enskog approximations after an appropriate selection of the collision integrals. The accuracy of the results is then discussed and some of the results have been compared with experiments.

1. Introduction. - The transport coefficients of $\mathrm{N}_{2}$ and of $\mathrm{H}_{2}$ plasmas as well as of their mixtures are required for many applications such as reentry heat transfer, plasmachemistry and the physics of electrical discharges.

Although the properties of pure gases have been extensively tabulated in $[1,2]$, many problems are still to be overcome to obtain accurate results. Some of these problems, which were already pointed out in $[1,2]$, such as a better knowledge of the resonant charge transfer cross-section

$$
\mathrm{N}\left({ }^{4} \mathrm{~S}\right)+\mathrm{N}^{+}\left({ }^{3} \mathrm{P}\right)=\mathrm{N}^{+}\left({ }^{3} \mathrm{P}\right)+\mathrm{N}\left({ }^{4} \mathrm{~S}\right)
$$

and a new experimental determination of the total thermal conductivity of hydrogen, have been recently accomplished [3, 4].

Their effects on the transport coefficients of atmospheric pure gases as well as on those of mixtures will be examined in the present work.

The plasma has been assumed to consist of seven species $\mathrm{N}_{2}, \mathrm{H}_{2}, \mathrm{~N}, \mathrm{H}, \mathrm{N}^{+}, \mathrm{H}^{+}$and electrons, the concentration of which has been obtained in [5] under

(*) Communication presented at the Conference on Plasma Physics, Paris, December 1976. the hypothesis of local thermodynamic equilibrium (LTE).

2. Method of calculation. - The total thermal conductivity of a multicomponent reacting mixture has been calculated as $[6,7]$

$$
\lambda_{\text {Tot }}=\lambda_{\mathrm{E}}+\lambda_{\mathrm{H}}+\lambda_{\mathrm{R}}+\lambda_{\text {int }}
$$

where the different terms represent the translational contribution due to the electrons $\left(\lambda_{\mathrm{E}}\right)$ and to the heavy components $\left(\lambda_{H}\right)$, the reactive $\left(\lambda_{R}\right)$ and internal $\left(\lambda_{\text {int }}\right)$ contributions.

The third and second approximations of the Chapman-Enskog (C-E) method have been respectively used for calculating $\lambda_{E}$ and $\lambda_{H}$, while $\lambda_{R}$ has been computed with the general Butler and Brokaw expression $[8]$ including the following reactions

$\mathrm{N}_{2} \rightleftarrows 2 \mathrm{~N} ; \mathrm{H}_{2} \rightleftarrows 2 \mathrm{H} ; \mathrm{N} \rightleftarrows \mathrm{N}^{+}+\mathrm{e} ; \mathrm{H} \rightleftarrows \mathrm{H}^{+}+\mathrm{e}$.

The Eucken method has been used for estimating the vibrorotational contribution to $\lambda_{\text {int }}$, while the corresponding contribution of the low lying excited states of nitrogen atoms (i.e. the ${ }^{2} \mathrm{D}$ and ${ }^{2} \mathrm{P}$ states) has been calculated as in [2]. 
Finally the first and the third approximations of the Chapman-Enskog method have been utilized for computing the viscosity and the electrical conductivity $[6,7]$. The collision integrals necessary for the present calculations are essentially those of ref. [2] for nitrogen interactions $\left(\mathrm{N}_{2}-\mathrm{N}_{2}, \mathbf{N}-\mathrm{N}_{2}, \mathrm{~N}-\mathrm{e}, \mathrm{N}^{+}-\mathrm{N}^{+}\right.$, e-e) and those of [6] for hydrogen interactions $\left(\mathrm{H}_{2}-\mathrm{H}_{2}\right.$, $\mathrm{H}-\mathrm{H}_{2}, \mathrm{H}-\mathrm{H}^{+}, \mathrm{H}-\mathrm{H}, \mathrm{e}-\mathrm{H}, \mathrm{H}^{+}-\mathrm{H}^{+}$). A shielded Coulomb potential has been used for calculating the collision integrals of charged-charged (including electron-electron) interactions. They appear in the form [7]

$$
\bar{\Omega}^{(1, \mathrm{~s})} \propto f(1, \mathrm{~s}) b_{0}^{2}(\ln \Lambda-0(1) \text { terms })
$$

where $\Lambda=2 d / b_{0}$ is the ratio between the Debye lenght $(d)$ and the average closest impact parameter $b_{0}$.

To the dominant $\ln \Lambda$ term, these formulas in connection with the third approximation to $\lambda_{E}$, give the same results (for a completely ionized gas) as those obtained by the Spitzer-Harm expression derived from the Fokker-Planck equation (see [7]).

The transport cross-section (diffusion type) of the interaction $\mathrm{N}-\mathrm{N}^{+}$have been derived from a recent calculation of resonant charge transfer cross-sections [3].

The new data are close (within $20 \%$ ) to those derived from the experimental charge transfer cross-sections of Belyaev et al. [9].

The interaction between $\mathbf{N}\left({ }^{4} \mathrm{~S}\right)-\mathrm{N}\left({ }^{4} \mathrm{~S}\right)$ occurs along four potentials $\left({ }^{1} \Sigma,{ }^{3} \Sigma,{ }^{5} \Sigma,{ }^{7} \Sigma\right)$. The last of these potentials (i.e. ${ }^{7} \Sigma$ ) has been recently calculated on the basis of the Heitler-London method [10] and used with the remaining potentials quoted in [2] for deriving a new set of $\left.\mathrm{N}^{4} \mathrm{~S}\right) \mathrm{N}\left({ }^{4} \mathrm{~S}\right)$ collision integrals.

The $\mathrm{N}_{2}-\mathrm{H}$ transport cross-section have been derived from the exponential repulsive potential [11] :

$$
V(r)=1740 \exp -(4.52 r) \mathrm{eV}
$$

with the aid of Monchik's tables [12].

The same potential has been used for $\mathrm{N}-\mathrm{H}_{2}$ interaction.

The inverse power potential (see table 18 of ref. [13])

$$
V(r)=88.1 / r^{6.63} \mathrm{eV}
$$

has been used for $\mathrm{N}_{2}-\mathrm{H}_{2}$ collisions.

The transport cross-sections of the interaction $\mathrm{N}\left({ }^{4} \mathrm{~S}\right)-\mathrm{H}\left({ }^{2} \mathrm{~S}\right)$ have been obtained by averaging the two contributions coming from the bound ${ }^{3} \Sigma$ potential and from the repulsive ${ }^{5} \Sigma$ one. A Morse and an exponential repulsive potential have been used for the two states; the necessary parameters have been obtained from the tabulations of [14].

Finally the collision integrals of $\mathrm{N}^{+}-\mathrm{H}$ and $\mathrm{N}-\mathrm{H}^{+}$ interactions have been put equal to the corresponding $\mathrm{N}-\mathrm{H}$ ones, while a polarizability model has been used for the $\mathrm{N}_{2}-\mathrm{H}^{+}$and $\mathrm{N}_{2}-\mathrm{N}^{+}$cases. The first approximation can be justified by the fact that in the energy range in which $\mathrm{N}^{+} \mathrm{H}$ and $\mathrm{NH}^{+}$interactions affect the transport coefficients $(T>10000 \mathrm{~K})$, the valence forces are more important than the corresponding forces acting at low temperature (i.e. charge-induced dipole for $\mathrm{N}^{+} \mathrm{H}, \mathrm{NH}^{+}$and induced dipole-induced dipole for $\mathrm{NH}$ ).

Selected values of transport cross-sections diffusion type are given in table I.

\section{TABLE I}

Collision (*) integrals of the diffusion type $\bar{\Omega}^{(11)}\left(\AA^{2}\right)$ for different interactions

$\begin{array}{rccccc}T \text { K } & \mathrm{N}_{2}-\mathrm{H} & \mathrm{N}_{2}-\mathrm{H}_{2} & \mathrm{~N}-\mathrm{H} & \mathrm{N}-\mathrm{N} & \mathrm{N}^{+} \mathrm{N}^{+} \\ 20 & - & - & - & - & - \\ 4000 & 3.64 & 5.56 & 5.24 & 5.53 & 22.62 \\ 6000 & 3.08 & 4.51 & 4.18 & 4.57 & 21.42 \\ 8000 & 2.78 & 4.00 & 3.52 & 4.10 & 20.74 \\ 10000 & 2.58 & 3.66 & 3.04 & 3.80 & 20.26 \\ 12000 & 2.42 & 3.42 & 2.70 & 3.56 & 19.90 \\ 14000 & 2.20 & 3.24 & 2.42 & 3.36 & 19.60 \\ 16000 & 2.11 & 2.97 & 2.22 & 3.19 & 19.35 \\ 18000 & 2.04 & 2.87 & 1.90 & 2.92 & 18.95 \\ 20000 & 1.97 & 2.78 & 1.78 & 2.81 & 18.78\end{array}$

$\left(^{*}\right)$ All values have been divided by $\pi$.

3. Results. - Values of the total thermal conductivity, of the viscosity and of the electrical conductivity are given as a function of the hydrogen molar fraction in figures 1-3 at different temperatures.

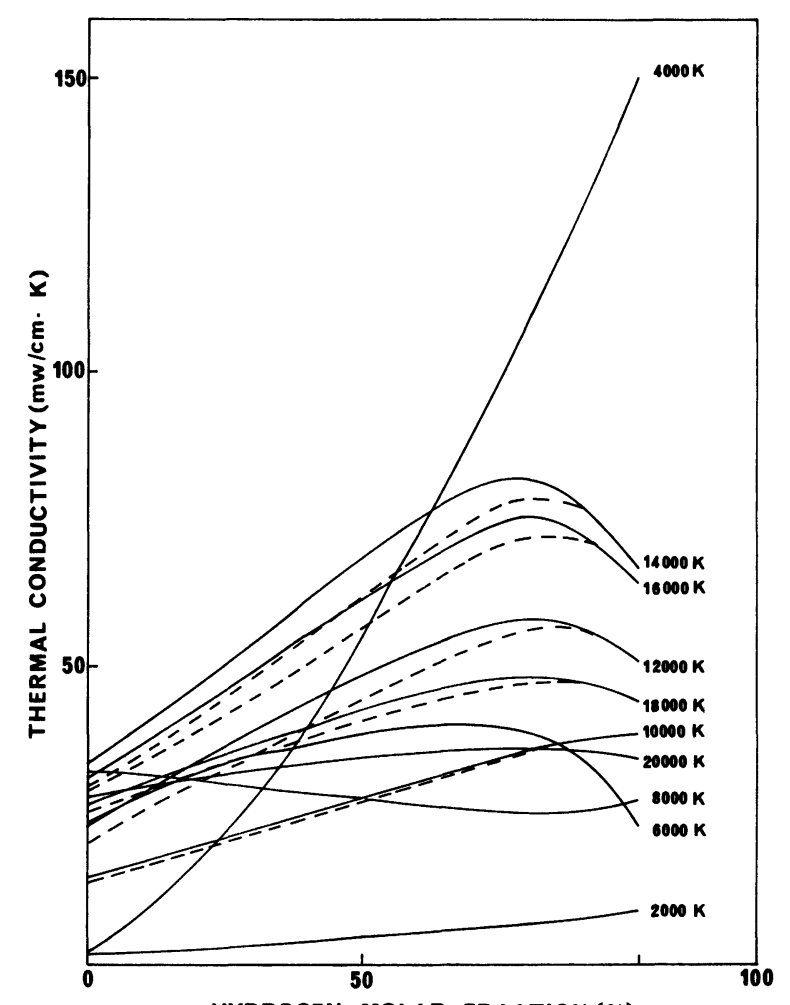

HYDROGEN MOLAR FRACTION (x)

FIG. 1. - Total thermal conductivity as a function of composition $\left(-\right.$ present results using $\Omega_{\mathrm{N}^{-N^{+}}}^{(11)}$ from [3]; . . . . the same with $\Omega_{\mathrm{N}-\mathrm{N}^{+}}^{(11)}$ from [9]). 


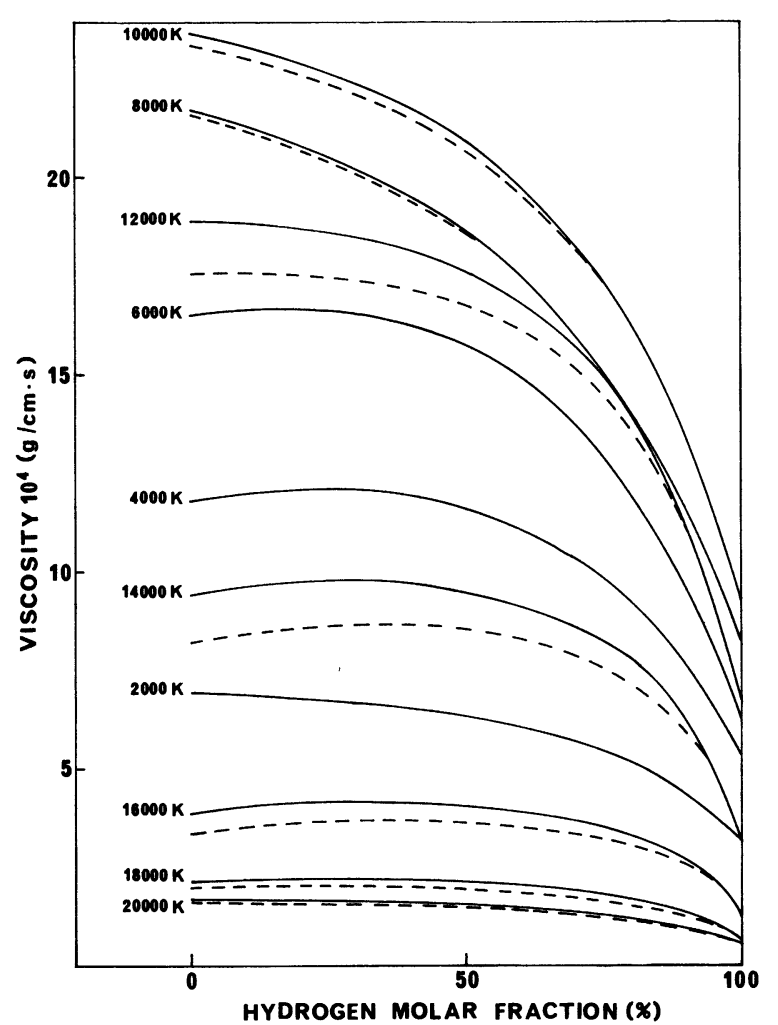

Fig. 2. - Viscosity as a function of composition (see Fig. 1).

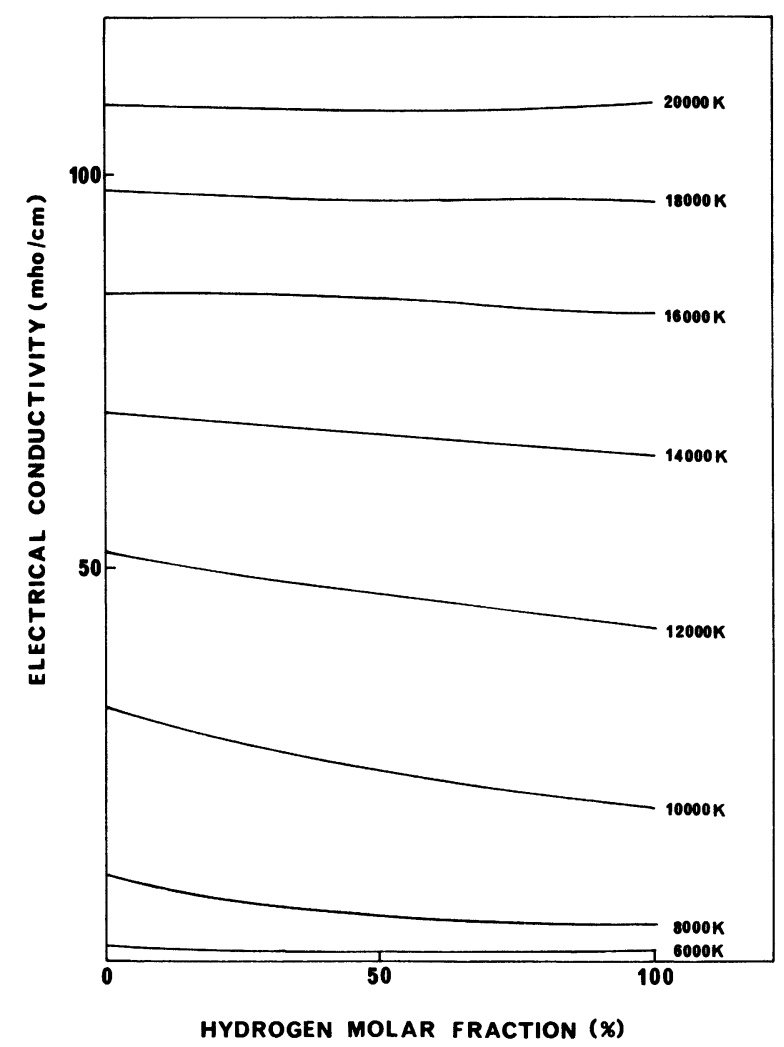

FIG. 3. - Electrical conductivity as a function of composition.

It should be noted that maxima of the total thermal conductivity occur in the region of partial ionization because of non-resonant ion-atom interactions $\left(\mathrm{N}^{+}-\mathrm{H}\right.$, $\mathrm{N}-\mathrm{H}^{+}$) that have collision integrals smaller than the corresponding resonant ones $\left(\mathrm{N}-\mathrm{N}^{+}, \mathrm{H}-\mathrm{H}^{+}\right)$. The increase of the thermal conductivity at $T=4000 \mathrm{~K}$ is a consequence of the peaks of the reactive contribution of the $\mathrm{H}_{2}=2 \mathrm{H}$ dissociation, which strongly increase with the hydrogen molar fraction (see for ex. [6]).

The behaviour of the viscosity curves, which strongly deviate from linearity is interesting as is the fact that small hydrogen concentrations increase the thermal conductivity, the reverse being true for the viscosity. As for the electrical conductivity, figure 3 shows that this quantity is practically independent of the mixture composition. This point can be understood by noting that the electrical conductivity strongly depends on the electron-electron collisions and on the electron number density $n_{\mathrm{e}}$. This last quantity in turn does not appreciably change with the $\mathrm{N}_{2}-\mathrm{H}_{2}$ composition.

Figure 4 shows the behaviour of the total thermal conductivity as a function of temperature for a $\mathrm{N}_{2}-\mathrm{H}_{2}$ mixture (3/1). There are strong variations of $\lambda_{\text {Tot }}$ at the onset of $\mathrm{H}_{2}(T \sim 2500 \mathrm{~K})$ and $\mathrm{N}_{2}$ $(T \sim 5500 \mathrm{~K})$ dissociations and for the ionization reactions $(T \sim 9000 \mathrm{~K})$ as a consequence of the corresponding dependence of the reactive contribution on the temperature. This last contribution is due to the diffusion of chemical enthalpy in the temperature gradient.

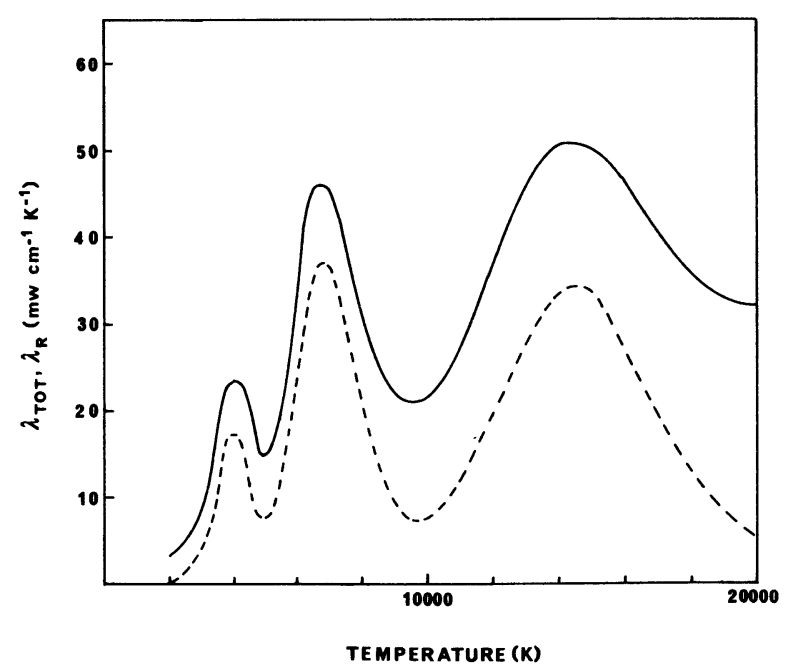

Fig. 4. - Total thermal conductivity (full lines) and reactive thermal conductivity (dashed lines) for a $\mathrm{N}_{2}-\mathrm{H}_{2}$ mixture $(3: 1)$ as a function of temperature.

The accuracy of the present calculations essentially depends on the adopted set of collision integrals. In this connection we note that the use of $\Omega_{\mathrm{N}^{-} \mathrm{N}^{+}}^{(1)}$ derived from the experimental charge transfer cross-sections of [9] affect $\lambda_{\text {Tot }}$ and $\eta$ by not more than $15 \%$ as compared with the present results based on the charge transfer cross-sections of [3] (see Fig. 1-2).

The importance of $\mathrm{N}^{+}-\mathrm{H}$ and $\mathrm{N}-\mathrm{H}^{+}$interactions have been numerically tested by increasing the corresponding transport cross-sections by a factor 
1.5. The response of the total conductivity and of the viscosity to this variation do not exceed $15 \%$ and $5 \%$ respectively in the temperature range $10000-20000 \mathrm{~K}$. Similar results have been obtained in the temperature range $2000-8000 \mathrm{~K}$ increasing by the same factor the collision integrals of $\mathrm{N}_{2}-\mathrm{H}, \mathrm{N}-\mathrm{H}_{2}$ interactions.

The accuracy of the results in the $\mathrm{H}_{2}$ dissociation region, depends on the collision integrals of $\mathrm{H}-\mathrm{H}_{2}$ interaction. In this work use has been made of the values of ref. [15], which have been found to be in good agreement with recent experiments [16].

Figure 5 shows a comparison of the total thermal conductivity of an atmospheric hydrogen plasma with the experimental values recently derived by Popovic and Konjevic [4], correcting the radial temperature distribution of [17]. In the same figure the theoretical values of [1] have also been given. One can note a satisfactory agreement between theory and experiment in the temperature range 13000 $22000 \mathrm{~K}$. The well known discrepancy between theory and experiments therefore seems to be removed (see [1])

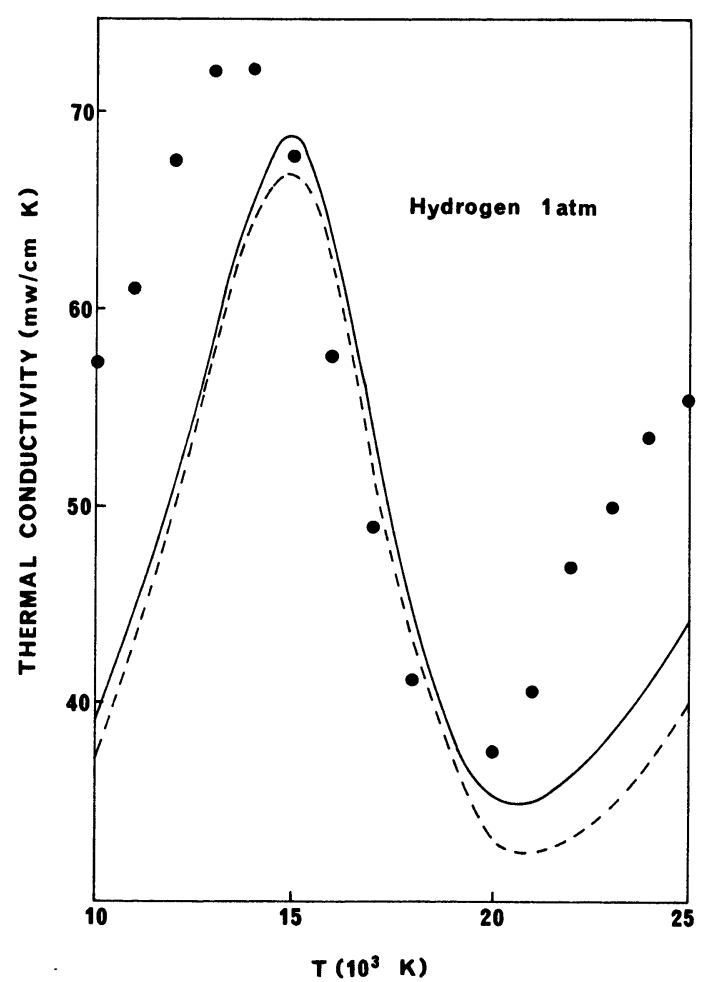

Fig. 5. - Total thermal conductivity as a function of temperature for $\mathrm{H}_{2}$ pure plasma ( $\longrightarrow$ present results ; ...... ref. [1] ; experimental [4])

Good agreement is also found for the electrical conductivity (see Fig. 6) as well as for the transport coefficients of pure nitrogen plasmas (see $[2,18]$ ). The results reported in figures 1-6 disregard the pre-

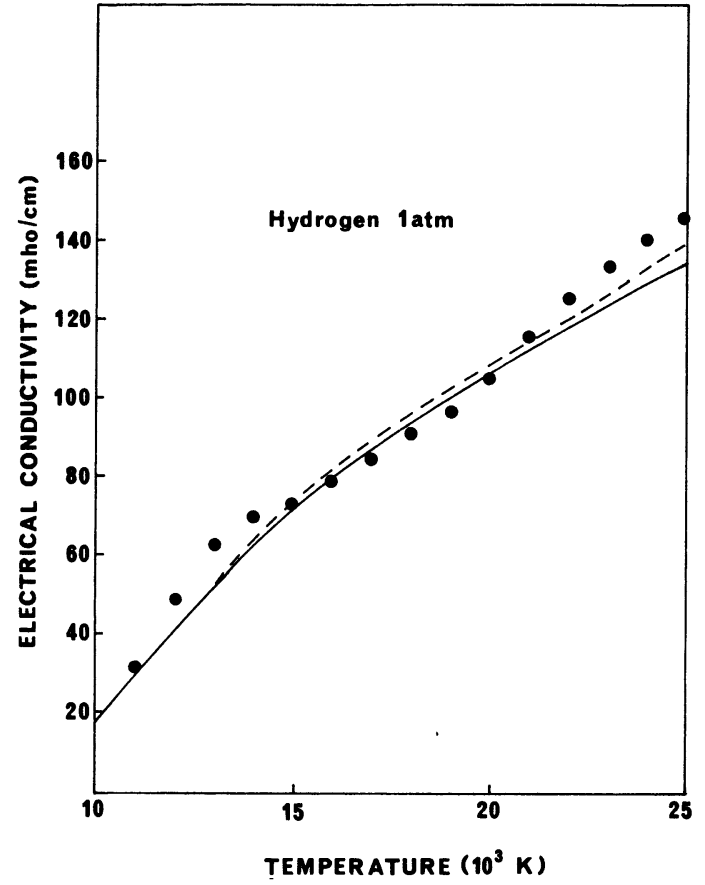

Fig. 6. - Electrical conductivity as a function of temperature for $\mathrm{H}_{2}$ pure plasma (see Fig. 5).

sence of electronically excited states, with the only exception being the inclusion of ${ }^{2} \mathrm{D}$ and ${ }^{2} \mathrm{P}$ nitrogen states. The insertion of these two states as new species in the plasma should not have strong effects on the translational thermal conductivity and on the viscosity of the mixture, since $\mathrm{N}\left({ }^{2} \mathrm{D}\right)-\mathrm{H}\left({ }^{2} \mathrm{~S}\right), \mathrm{N}\left({ }^{2} \mathrm{P}\right)$ $\mathrm{H}\left({ }^{2} \mathrm{~S}\right)$ collision integrals, calculated from the potentials of [14], do not differ much from the corresponding $\mathbf{N}\left({ }^{4} \mathrm{~S}\right)-\mathbf{H}\left({ }^{2} \mathrm{~S}\right)$ values (see table II).

On the contrary a greater influence is expected from the high lying excited states of hydrogen and nitrogen atoms, as recently shown in [19]. Their effects are however important for $T>15000 \mathrm{~K}$.

\section{TABLE II}

Collision $\left(^{*}\right)$ integrals of the viscosity type $\bar{\Omega}^{(22)}\left(\AA^{2}\right)$ for $\mathrm{N}-\mathrm{H}$ interactions in different electronic states

$\begin{array}{rccc}T \mathrm{~K} & \mathrm{~N}\left({ }^{4} \mathrm{~S}\right)-\mathrm{H}\left({ }^{2} \mathrm{~S}\right) & \mathrm{N}\left({ }^{2} \mathrm{D}\right)-\mathrm{H}\left({ }^{2} \mathrm{~S}\right) & \mathrm{N}\left({ }^{2} \mathrm{P}\right)-\mathrm{H}\left({ }^{2} \mathrm{~S}\right) \\ - & - & - & - \\ 6000 & 4.02 & 3.51 & 3.28 \\ 8000 & 3.58 & 3.12 & 2.92 \\ 10000 & 3.23 & 2.83 & 2.70 \\ 12000 & 2.94 & 2.61 & 2.54 \\ 14000 & 2.72 & 2.42 & 2.40 \\ 16000 & 2.52 & 2.27 & 2.27 \\ 18000 & 2.35 & 2.14 & 2.17 \\ 20000 & 2.21 & 2.03 & 2.10\end{array}$

$\left.{ }^{*}\right)$ All data have been divided by $\pi$. 


\section{References}

[1] Devoto, R. S., J. Plasma Phys. 2 (1968) 617.

[2] Capitelli, M. and Devoto, R. S., Phys. Fluids 16 (1973) 1835.

[3] Capitelli, M., lamanna, U., Guidotti, C. and Arrighini, P., Chem. Phys. 19 (1977) 269.

[4] Popovic, S. and Konjevic, N., Z. Naturforsch. 31a (1976) 1042.

[5] Fauchais, P., Rapport Interne de la faculté des Sciences de Poitiers 212 (1967).

[6] Capitelli, M., Gorse, C. and Fauchais, P., J. Chim. Phys. 73 (1976) 755.

[7] Devoto, R. S., Phys. Fluids 10 (1967) 2105.

[8] Butler, J. N. and Brokaw, R. S., J. Chem. Phys. 26 (1956) 1636.

[9] Belyaev, V. A., Brezhnev, B. G. and Erastov, E. M., Sov. Phys. JETP 27 (1968) 198.
[10] Guidotti, C., Arrighini, P., Capitelli, M. and lamanna, U., Z. Naturforsch. 319 (1976) 1722.

[11] Leonas, V. B., Sov. Phys. Usp. 15 (1973) 266.

[12] MonchiK, L., Phys. Fluids 2 (1959) 695.

[13] Marrero, T. R. and Mason, E. A., J. Phys. Chem. Ref. Data 1 (1972) 3.

[14] Kouba, J. and Ohrn, Y., J. Chem. Phys. 52 (1970) 5387.

[15] Vanderslice, J. T., Weismann, S., Mason, E. A. and FalLON, R. J., Phys. Fluids 5 (1962) 55.

[16] Stefanov, B. and Zarkova, L., J. Phys. D 9 (1976) 1217.

[17] Steimberger, S., Z. Phys. 223 (1969) 1.

[18] Capitelli, M., J. Physique Colloq. 38 (1977) C3.

[19] Capitelli, M. and Lamanna, U., J. Plasma Phys. 12 (1974) 71 ; Z. Naturforsch. 29a (1974) 954. 